\title{
OS MOVIMENTOS DE RENOVAÇÃO POLÍTICA E A PROMOÇÃO DA PARTICIPAÇÃO DA MULHER NAS ELEIÇÕES DE 2018
}

\author{
The political renewal movements and the promotion of women's participation \\ in the 2018 Elections
}

Níkolas Reis Moraes dos Santos

Vanessa de Ramos Keller

Resumo: Este artigo é resultado de pesquisa bibliográfica, de colheita e tratamento de dados, e de estudo de casos em que se buscou tratar os dados e as informações identificados nas literaturas histórica, sociológica, política e jurídica local, nacional e internacional, bem como em indicadores e informações oficiais, tendo como Norte a participação da mulher no processo eleitoral, e a dimensão da importância das instituições, enquanto movimentos de renovação política, especialmente a RAPS, a Fundação Lemann e o RenovaBR, na promoção de tal participação, do que se concluiu que é preciso estimular tais movimentos suprapartidários que já alcançam resultados relevantes. Utilizou-se, para tanto, da técnica do referente e aplicou-se o método indutivo.

Palavras-chave: Democracia. Participação feminina. Renovação política.

\begin{abstract}
This paper is the result of a bibliographical research, data collection and processing, as well as case studies research, seeking to treat data and informations identified in the sociological, political and legal literature, locally, nationally and internationally, as well as in official indicators and information, aiming at the women's involvement in the electoral process, and the dimension of the importance that the political renewal movements, especially RAPS, RenovaBR and Lemann Foundation, have on this subject, from what it was concluded that these institutions, as political movements, have achieved relevant outcomes and should be encouraged to continue to do so. For that, it was used the technique of referent and the inductive method. Keywords: Democracy. Women's political participation. Political renewal.
\end{abstract}

Artigo recebido em 22 jul. 2019 e aprovado em 11 ago. 2019. 


\section{Introdução}

São pressupostos evidentes, mas que ainda assim serão abordados teoricamente neste artigo, que a participação das mulheres nos cargos eletivos é inexpressiva do ponto de vista quantitativo, e carece de estudos que se proponham mais e mais a compreenderem as razões da baixa adesão feminina aos quadros partidários e às listas eleitorais. Além disso, Há que se rever a baixa adesão dos eleitores às candidaturas femininas que são postas, bem como para que sirvam de instrumento para o desenvolvimento de uma narrativa e de ações já existentes, mas incipientes de construção de um novo momento da Democracia com vistas a melhores práticas de governança a partir da participação - no mínimo - paritária com os homens.

É que os números são assustadores na prática e na teoria. A título de exemplo, a Câmara Municipal de Itajaí, Santa Catarina, desde sua primeira legislatura, em 1860, até a presente, iniciada em 2017, contou com um total de 308 cidadãs e cidadãos que ocuparam a titularidade das cadeiras, sendo que, apenas 17, em um período de 159 anos, foram mulheres, o que corresponde a $5 \%$ do total. Nessa cidade, ainda, nunca uma mulher foi eleita ou ocupou a titularidade da chefia do Poder Executivo local. (ESMERALDINO, 2012, p. 71-89). É verdade que a proporção de parlamentares mulheres melhorou, mas ainda é flagrantemente menor que a de homens, e a atual legislatura - 2017-2020 - possui somente 03 vereadoras em um universo de 21 assentos, ou seja, apenas 14\% do parlamento local é ocupado por mulheres. Ainda em Santa Catarina, importantes cidades, como Joinville e Florianópolis, registram, na atual legislatura, 15\% e 04\% de participação feminina, respectivamente. Blumenau, por sua vez, tem sua Câmara composta $100 \%$ por homens. A título comparativo, as Câmaras Municipais das capitais de São Paulo e da Bahia contam com 16\% de cadeiras ocupadas por mulheres. A Assembleia Legislativa de Santa Catarina tem 05 deputadas em um universo de 40 cadeiras, o que resulta numa proporção de representação de apenas $12 \%$ de mulheres. No Congresso Nacional, tomando por base a eleição geral de 2018, o Senado Federal recebeu 07 mulheres contra 47 homens, e a Câmara dos Deputados recebeu 77 mulheres para 436 homens, o que se traduz em proporções de 13\% e 15\% respectivamente. Ainda tendo como base a eleição geral de 2018, por fim, apenas 01 mulher foi eleita para governar um estado brasileiro: Fátima Bezerra, no Rio Grande do Norte. E, embora não seja objeto da pesquisa, mas ainda para ilustrar que o mesma se 
justifica, em boa parte dos casos, mesmo as mulheres eleitas reproduzem ou mesmo promovem uma narrativa machista que não contribui sequer para a manutenção desses percentuais, quanto mais para que se alcance a paridade.

Delimita-se, ora, o tema deste trabalho, que se insere em um daqueles propostos, ou seja: modelos teóricos de promoção da participação feminina na política e experiências comparadas, com ênfase nessas experiências comparadas. O recorte temporal é a análise contemporânea de tal tema, inclusive e tendo como pano de fundo uma crise da Democracia Liberal que atinge sistemas políticos de governo de todo o mundo e do Brasil. Tema e recorte temporal, por sua vez, serviram como referente geral ${ }^{1} \mathrm{da}$ pesquisa, de modo que o problema que se apresentou é se as instituições RAPS - Rede de Ação Política pela Sustentabilidade, Fundação Lemann e RenovaBR, enquanto Movimentos de Renovação Política, contribuíram ou não para a melhoria da representação feminina nos espaços de poder, com enfoque na eleição geral de 2018, sendo que a hipótese confirmada sugere que sim, ainda que em modesta medida.

O objetivo geral do estudo, dessa forma, foi o de examinar essas três entidades, a partir da colheita e do tratamento de dados e informações disponíveis em suas páginas oficiais, e, por sua vez, descrever os resultados obtidos, tendo como Norte o referente destacado. Os objetivos específicos, de revisar a literatura e identificar e analisar em autores de ressonância nacional e internacional dos campos da História, da Sociologia, da Ciência Política e do Direito, bem como em indicadores e informações oficiais, como a promoção da participação da mulher nos processos eleitorais, tem se apresentado. Por fim, investigar e propor soluções de aprimoramento da Democracia pela via da ocupação feminina dos espaços de poder eletivos. O método utilizado foi o indutivo; a natureza da pesquisa é básica; a abordagem do problema, qualitativa. os objetivos, descritivos e prescritivos; e o procedimento técnico bibliográfico, de estudo de casos e de análise de dados. As categorias fundamentais do trabalho, cujos conceitos operacionais se apresentam ao longo do texto, assim, são: a Democracia; a Democracia Liberal; a Democracia Paritária; a Accountability Democrática; os Movimentos de Renovação Política; o Feminismo; e a Participação da Mulher na Política.

\footnotetext{
${ }^{1}$ Metodologia por PASSOLD, César Luiz. Metodologia da Pesquisa Jurídica: teoria e prática. 13. ed. Florianópolis: Conceito editorial, 2015.
} 
Os objetos de estudo são a Participação da Mulher na Política e os Movimentos de Renovação Política, e a revisão bibliográfica se deu a partir de autoras e autores dedicadas e dedicados ao estudo desses objetos, bem como dos desenhos institucionais dos Estados contemporâneos, sobretudo ocidentais e/ou com influência ocidental.

Este artigo assim se divide, além dessa Introdução e das Considerações Finais, em dois tópicos, um dos quais se subdivide em dois, e outro, em três, quais sejam (considerando a Introdução como 1): 2. A crise da democracia e a participação da mulher: uma revisão da literatura; $2.1 \mathrm{Da}$ importância do movimento feminista na efetivação dos direitos políticos das mulheres; 2.2 Da sub-representação feminina na política. 3. Estudos de caso e análise de dados; 3.1 A RAPS; 3.2 A Fundação Lemann; e 3.3 O RenovaBR.

\section{A crise da democracia e a participação da mulher: uma revisão da literatura}

Democracia significa que deveria haver eleições periódicas (ou regulares) e legítimas, e que o poder pode e deve trocar de mãos pelo voto popular e não pela coerção nem pela força (SISK, 2015, p. 24). A Democracia Liberal é simplesmente um sistema político ao mesmo tempo liberal e democrático - um sistema que tanto protege os direitos individuais como traduz a opinião popular em políticas públicas (MOUNK, 2019, p. 44). Da revisão das literaturas histórica, política e sociológica mais recentes, nota-se um consenso presente em todas as obras analisadas, o de que a Democracia, para alguns, e mais especificamente a Democracia Liberal, para outros, encontra-se em recessão, em retrocesso, em crise, ou mesmo em colapso. Castells (2018, p. 10) aponta para um "colapso gradual de um modelo de representação". Mounk (2019, p. 16), por sua vez, destaca fazer tempo que "os sistemas partidários parecem paralisados". Ainda segundo ele, "hoje, o populismo autoritário cresce no mundo todo, da América à Europa, e da Asia à Austrália”. Já para Harari (2018, p. 24), no que toca a influência da internet na vida política das sociedades, "o sistema democrático ainda está se esforçando por entender o que o atingiu, e está mal equipado para lidar com os choques seguintes [...]”. Levitsky e Ziblatt (2018, p. 17), por fim, encaminham seus diagnósticos na mesma direção, e afirmam que "a erosão da democracia é, para muitos, quase imperceptível". 
Dos autores nacionais revisados, D’Avila (2017, p. 51), aponta para o fato de que "o modelo centralizador e patrimonialista triunfou, o que revela os desafios da nação para rever crenças obsoletas que impedem o progresso do país". E Abranches (2018, p. 9), para o fato de que "a democracia vai mal em todo o mundo", e de que "a crise de representação é global"'.

Tais autores, nacionais e internacionais, possuem pontos em comum e divergentes, mas a superação da crise pelo aprimoramento da própria Democracia é um dos elementos que convergem. Accountability democrática é o que garante que o governo aja de acordo com os interesses de toda a comunidade (FUKUYAMA, 2008, p.8) e está presente literal ou intrinsecamente nas obras analisadas, e mesmo em outras, revisadas. Putnan (2015, p. 17), para quem “o autogoverno democrático requer uma cidadania ativamente engajada”, e, ainda, Wolkmer (2003, p. 95), que já afirmava na virada do século que era necessário reconhecer a crise da representação e redefinir o paradigma "em função de uma nova cultura política, fundada na participação dos sujeitos coletivos emergentes”, são alguns dos autores que fundamentam a assertiva que se apresenta.

Mas nenhum desses autores, todos com diagnósticos assentados no realismo e prognósticos no idealismo, entusiastas da Accountability democrática, cada um ao seu modo, apontam a Participação da Mulher na Política como uma das maneiras de suplantar a crise. Para fins deste trabalho, esse é um pressuposto central de contribuição para a superação da crise e se relaciona necessariamente com o conceito anterior, passando para a análise da literatura especializada, destacando-se, desde já, que o conceito operacional para a categoria Participação da Mulher na Política é que a mesma se refere tanto à ocupação feminina nos órgãos de direção partidária, como nas chapas eleitorais majoritárias e proporcionais, e, sobretudo, da efetiva ocupação feminina na titularidade dos cargos eletivos para os poderes Executivo e Legislativo.

\subsection{Da importância do movimento feminista na efetivação dos direitos políticos das mulheres}

Feminismo é uma teoria sobre a distribuição desigual do poder nas sociedades humanas. Assim, o Feminismo compreende movimentos políticos e sociais que pretendem construir direitos iguais para os seres humanos na sociedade. São teorias e filosofias que pregam a igualdade entre 
homens e mulheres, além de promover a construção dos direitos das mulheres. Ou de uma percepção coletiva das mulheres de que existe opressão, dominação e exploração de que foram e são objetos de sujeição por parte dos homens (MELO e THOMÉ, 2018, 1. 204).

Democracia Paritária, por sua vez, se dá em um contexto de crescente reconhecimento da forma desigual que mulheres e homens ocupam espaços de tomada de decisão - particularmente na política. A democracia paritária apresenta-se como um modelo político no qual a paridade e a igualdade substantiva se constituem como elementos fundantes do Estado inclusivo e paritário. A democracia paritária implica profundas transformações qualitativas e quantitativas, que incluem desde a participação política feminina até o enfrentamento das variadas violações de direitos contra mulheres e meninas (ONU, 2019).

Ainda que não seja o foco principal desta pesquisa, não há como se falar em Participação da Mulher na Política sem abordar o movimento feminista e o papel decisivo que teve ao longo da história para a efetivação dos direitos políticos das mulheres. Por isso, ainda que de maneira muito breve e superficial, far-se-á um simples relato sobre a relação estreita entre feminismo e política.

Sabe-se que, na maioria das sociedades, as diferenças e as desigualdades entre homens e mulheres são um traço marcante. Embora nos últimos dois séculos essa desigualdade tenha sido debatida e combatida, pode-se afirmar que, ao longo da História, ela foi assumida "como um reflexo da natureza diferenciada dos dois sexos e necessária para a sobrevivência e o progresso da espécie". Foi na recusa dessa compreensão estabelecida que o movimento feminista ganhou voz e força, denunciando a situação das mulheres como consequência de padrões opressores, caminhando, desta forma, "para uma crítica ampla do mundo social, que reproduz assimetrias e impede a ação autônoma de muitos de seus integrantes" (BIROLI e MIGUEL, 2014, 1. 235).

O movimento feminista, como bem observa Miguel (2014, 1. 280), "se definiu pela construção de uma crítica que vincula a submissão da mulher na esfera doméstica à sua exclusão da esfera pública”. Dessa forma, ainda de acordo com a visão do autor, o feminismo surge como "movimento político e intelectual na virada do século XVIII para o século XIX e pode ser considerado um filho indesejado da Revolução Francesa”. 
No mundo ocidental, costuma-se classificar o movimento feminista em três grandes ondas ou fases. De acordo com Gohn (2007, p. 46), a primeira fase está relacionada à luta pelo reconhecimento legal da igualdade de direitos, como o direito ao voto e ao trabalho, nos séculos XVIII e XIX e início do século XX. Já a segunda fase refere-se especialmente ao período compreendido entre 1960 e 1980, tempo em que, além da preocupação com a igualdade, acentuou-se também a preocupação com os costumes, trazendo-se o foco das discussões e debates para temas como sexualidade, violência, mercado de trabalho, etc. Foi neste período também que surgiu a categoria "gênero". A terceira fase teve início em 1990, quando entra em destaque a crítica pela forma como os meios de comunicação em massa construíam a imagem feminina, de modo que o movimento feminista passou a falar não apenas sobre a sexualidade da mulher, mas em nome de uma libertação dessa sexualidade.

No Brasil, foi entre os anos de 1830 e 1840 que apareceram os primeiros registros sobre figuras importantes para as lutas feministas no país, nos quais merece destaque o nome de Nísia Floresta Brasileira Augusta, que em 1835 publicou o livro Direito das mulheres e injustiça dos homens, no qual "defendia o direito das mulheres à educação, denunciava a ignorância em que eram mantidas as meninas e protestava contra a condição de dependência a qual eram relegadas as mulheres em relação aos homens" (MELO e THOMÉ, 2018, 1. 733).

$\mathrm{Na}$ luta pelo reconhecimento dos direitos políticos das mulheres no Brasil, merece destaque o nome de Leolinda de Figueiredo Daltro, que, juntamente com outras feministas, fundaram, em dezembro de 1910, no Rio de Janeiro, o Partido Republicano Feminino, precursor na organização das mulheres brasileiras na luta pelo sufrágio eleitoral. Durante toda década, Leolinda e suas companheiras ocuparam a cena política carioca, organizando marchas e conferências, levando ao debate a questão eleitoral e a cidadania incompleta das mulheres na Primeira República (MELO e THOMÉ, 2018, 1. 837-838).

Em 1920, Julita Monteiro Soares, acompanhando os passos de Leolinda, registrou o Partido Liberal Feminino. Embora tenha sido uma década de muita efervescência e de episódios importantes na luta feminista pelos direitos políticos das mulheres, somente em 1932, no governo de Getúlio Vargas, foi assinado o Código Eleitoral Provisório (24 de fevereiro de 1932), concedendo o direito de voto às mulheres. Motivadas pela conquista, 
as mulheres tiveram participação ativa na ebulição política desse período e marcaram sua presença nos pleitos eleitorais de 1933 e 1934, concorrendo a vagas como deputadas federais e estaduais, prefeitas e vereadoras. Infelizmente, obtiveram menos sucesso do que o desejado (MELO e THOMÉ, 2018, 1. 878).

Como se pode observar, durante muitas décadas o foco principal do movimento feminista foi a conquista do direito de votar e ser votada. "Da metade do século XIX até as primeiras décadas do século XX, o sufragismo foi a face pública das reivindicações feministas" (BIROLI e MIGUEL, 2014, 1. 1924). Após essa conquista emblemática, muita coisa mudou em relação às batalhas do movimento feminista e ao reconhecimento dos direitos das mulheres de um modo geral, mas em termos de efetivação da representação feminina na política, ainda havia muito pouco a se comemorar.

\subsection{Da sub-representação feminina na política}

Miguel (2014, 1. 1953) afirma que "nas décadas finais do século XX, o problema da sub-representação das mulheres nas esferas de exercício do poder tornou-se uma prioridade na agenda feminista". De acordo com o autor, na tentativa de superar o problema da baixa representação das mulheres no Poder Legislativo, foram implementadas cotas eleitorais por sexo em diversos países, o que, como se verá adiante, não foi suficiente para alcançar uma representação mais igualitária, nem ao menos mais equilibrada, entre homens e mulheres na política.

Em termos de legislação no Brasil, o sistema de cotas eleitorais por sexo surgiu com a Lei ํㅡ 9.100 de 1995, a qual estabeleceu que 20\% das vagas nas listas partidárias para as Câmaras de Vereadoras deveriam ser preenchidos por mulheres, independentemente do critério de cor/raça. Posteriormente, a Lei no 9.504 de 1997 aumentou para 25\% a cota e a expandiu para todas as Assembleias e Câmara dos Deputados. No ano de 1998, a cota passou para 30\%. Anos mais tarde, a Lei no 12.034 de 2009 determinou o preenchimento mínimo de $30 \%$ das vagas dos partidos políticos com candidaturas femininas. Conhecida como minirreforma eleitoral, tal legislação determinou ainda a obrigação de que os partidos destinem ao menos $05 \%$ do fundo partidário para programas de promoção e difusão da participação política das mulheres, bem como pelo menos 10\% do tempo de rádio e TV para promover a participação política feminina (MELO e THOMÉ, 2018, 1. 2630-2638). 
Porém, como bem observam as mesmas autoras, na prática as cotas não desempenham um papel decisivo nas eleições, já que as candidaturas femininas não contam com grande apoio dos partidos políticos, o que as torna pouco competitivas. As autoras destacam, ainda, o fato de que muitas das candidatas atuam apenas como "laranjas" para o sistema, de forma que seus nomes são incluídos pelos partidos apenas como forma de cumprir a cota, carecendo de incentivos ou recursos para realizarem suas campanhas - o que se comprova, aliás, pelo número significativo de candidatas que não recebem um voto sequer. A respeito do papel das cotas nas eleições, as autoras afirmam que "esta é uma política afirmativa conquistada pelos movimentos feministas, mas de implementação ainda incompleto". Para elas, a efetivação das cotas no Brasil é, portanto, mais um desafio, uma vez que, em uma competição em lista aberta e bastante concentrada nos indivíduos, há menos incentivos para investimentos partidários nas candidatas mulheres (MELO e THOMÉ, 2018, 1. 2656).

Ainda de acordo com as autoras, o que dificulta em grande parte o sucesso das mulheres nas disputas por cargos eletivos são as barreiras encontradas pelo caminho que as mantêm alijadas da esfera de poder. As autoras afirmam que a perpetuação da predominância masculina no acesso a essas vagas é, em realidade, reflexo "de uma estrutura de dominação estabelecida na sociedade e que conta com o endosso e retroalimentação de todos os partícipes". Dessa forma, acaba por parecer natural que os homens dominem as estruturas de poder, o que, de fato, é apenas resultado do processo histórico (MELO e THOMÉ, 2018, 1. 3112).

Visando implementar medidas com o objetivo de alcançar uma participação mais igualitária na política entre homens e mulheres, em 2013, o Parlamento Latino-Americano e Caribenho - PARLATINO, com o apoio técnico da ONU Mulheres, elaborou e aprovou uma Resolução sobre a Participação Política das Mulheres. Após o início deste processo, em 2014, a ONU Mulheres elaborou o "Guia de Empoderamento Político das Mulheres: Marco para a Ação Estratégica na América Latina e Caribe - 2014/17”, incluindo uma normatização internacional e regional dos direitos políticos das mulheres.

O Marco Normativo para Consolidar a Democracia Paritária foi aprovado em Assembleia Geral no PARLATINO, em 26 de novembro de 2015, tendo como objetivo principal estabelecer a Democracia Paritária como modelo de Democracia, difundido e implementando-se a ideia de 
que os eixos estruturantes de um Estado inclusivo são a paridade e a igualdade substantiva entre mulheres e homens. Desta forma, o Marco Normativo se apresenta como uma ferramenta de fundamental importância para que se estabeleça um novo arranjo social capaz de eliminar todas as formas de exclusão do sexo feminino, fomentando e impulsionando a igualdade entre homens e mulheres, e promovendo a responsabilidade compartilhada em todas as esferas de suas vidas. Por outro lado, "o Marco Normativo prevê que a construção da igualdade substantiva e da paridade exija forte vontade política, assim como adequada alocação de recursos financeiros" (ONU, 2019).

Embora não possua um caráter obrigatório ou vinculante, o Marco Normativo para Consolidar a Democracia Paritária se apresenta como um guia-orientador de diretrizes a serem adotadas pelos países para a persecução do objetivo de alcançar igualdade entre homens e mulheres nos espaços políticos e decisivos dos Estados Democráticos, ao mesmo tempo em que possui um caráter sensibilizador e pedagógico no sentido de impulsionar a Democracia Paritária como um fim aos que almejam um Estado garantidor de direitos e cidadania.

Para corroborar e destacar a importância da implementação e persecução das metas e objetivos apresentados no Marco Normativo para Consolidar a Democracia Paritária, a ONU Mulheres e o PARLATINO apresentam, em sua "Nota Sobre Democracia Paritária", números que demonstram a baixa representatividade das mulheres na política, nos quais o Brasil é apontado como um destaque negativo, não apenas em termos regionais, mas também em termos globais. De acordo com o documento, em março de 2017, a ONU Mulheres, em parceria com a União Interparlamentar (UIP), lançou um panorama sobre a participação política de mulheres no mundo. $\mathrm{Na}$ época, com apenas uma ministra, o Brasil ocupava a $167^{\mathrm{a}}$ posição no ranking mundial de participação de mulheres no Executivo, entre os 174 países analisados. No que diz respeito ao Congresso, o país ficou na 154르 posição, com 55 das 513 cadeiras da Câmara ocupada por mulheres $(10 \%)$ e 12 dos 81 assentos no Senado (14\%).

\section{Estudos de caso e análise de dados}

Não se identificou na literatura pesquisada um conceito operacional para Movimentos de Renovação Política, termo cunhado pela imprensa, mas ainda em desenvolvimento, de modo que, para fins deste artigo, são 
iniciativas de entidades da sociedade civil com vistas à seleção de potenciais candidatas e candidatos a cargos eletivos, avaliando suas capacitações mediante critérios fundados em um diagnóstico da necessidade de melhoramento qualitativo da Democracia e de sua representação. É preciso destacar que, além dos aspectos em análise neste Movimento, há outros com vieses semelhantes que também foram identificados no Brasil e constituídos nos últimos anos, sobretudo a partir de 2012, e mais intensamente a partir de 2017, como o Acredito, o POLITIZE, o Agora, o Transparência Partidária e o Livres, além certamente de outros.

Apresentam-se, assim, duas questões metodológicas importantes antes da descrição das análises de tais movimentos. A primeira, relativa ao próprio termo e conceito operacional apresentado, no sentido de que a adoção dos mesmos se dá puramente para garantir fluidez ao texto, do que se destaca desde já a necessidade de se desenvolverem ambos, o que se deixa também desde já como sugestão para futuras pesquisas. A segunda, relativa ao critério subjetivo de seleção dos três movimentos em análise, no sentido de elegê-los dentre os outros identificados, e se deu por uma questão de necessidade de corte dada à natureza básica da pesquisa, mas que guarda relação também com o conceito operacional adotado, já que esses movimentos têm todos os componentes do conceito em comento em comum. De qualquer forma, acrescenta-se que também merecem ser estudados mais a fundo em outros trabalhos, já que, igualmente relevantes, ao menos potencialmente, tanto para o fim do melhoramento da Democracia brasileira como para a Participação da Mulher na Política nacional.

\subsection{A RAPS - Rede de Ação Política pela Sustentabilidade}

O primeiro estudo de caso se debruça sobre a RAPS, que, do ponto de vista jurídico, é uma entidade da sociedade civil, constituída no ano de 2012, que tem como presidente do Conselho Diretor o empresário Guilherme Leal, seu principal idealizador. Financia-se através de doações exclusivamente de pessoas físicas, 545 no total atualizado até a finalização deste texto. Como movimento, é uma rede de líderes políticos, com mandato ou não, empreendedores cívicos, ou seja, representantes de entidades do terceiro setor, e jovens interessados ou na política ou na atuação em organizações da sociedade civil. Designa-se suprapartidária e a seleção se dá por processo seletivo, sendo que os escolhidos passam por módulos de formação que incluem temas caros à Democracia, à governança, à sustenta- 
bilidade e às campanhas eleitorais, e comprometem-se através de um documento a atuarem pautados por determinados valores éticos e sustentáveis. São 576 lideranças em todo o Brasil, pertencentes a 29 partidos políticos diferentes, sendo que 134 com mandatos eletivos: 26 deputados federais; 26 deputados estaduais; 02 deputados distritais; 6 senadores; 2 governadores; 54 vereadores; 14 prefeitos; e 04 vice-prefeitos.

Em termos literais, extrai-se da apresentação em sua página que a Rede de Ação Política pela Sustentabilidade - RAPS é uma organização pioneira na política brasileira, fundada em maio de 2012, cuja missão é contribuir para a melhoria da qualidade da democracia no país. Isso é feito mediante atração, seleção, formação, apoio e monitoramento de lideranças políticas - com e sem mandatos eletivos - comprometidas com a ética, a transparência e a sustentabilidade (RAPS, 2019).

Seu Conselho Diretor é composto por 11 membros, sendo 09 homens e 02 mulheres. O Conselho Consultivo por 05 membros, sendo 04 homens e 01 mulher. $\mathrm{O}$ Conselho Fiscal tem 03 membros, 02 homens e 01 mulher. E o Conselho de Ética, 04 membros, 02 homens e 02 mulheres. A diretora executiva da Rede é uma mulher, e a equipe executiva é composta por 20 membros, das quais 15 são mulheres.

$\mathrm{Na}$ eleição geral de 2018, foram eleitos por diferentes partidos políticos a diferentes cargos eletivos, 38 líderes RAPS, sendo que, destes, 09 foram mulheres, uma proporção de $23 \%$ do total, número razoável se comparado com a realidade nacional. Do total da rede, que, como se viu, é composta por 576 lideranças, 214 são mulheres, o que representa percentualmente $37 \%$ do total de membros.

Mais antigo dos movimentos analisados neste artigo - sob o ponto de vista da renovação política, a RAPS, no entanto, apresenta uma evolução nos seus processos de seleção sob os paradigmas da Participação da Mulher na Política e da Democracia Paritária, e o último processo seletivo, o $7^{\circ}$ de sua história, contou com um total de 64 lideranças aprovadas, sendo $53 \%$ mulheres. Em 2018, o $6^{\circ}$ processo seletivo, a proporção havia sido de $40 \%$ de mulheres; no de 2017 , o $5^{\circ}$ processo de seleção, de $41 \%$; e no de 2016, o $4^{\circ}$ processo, de $28 \%$, de modo que a curva é ascendente e alcançou-se a paridade.

Deve-se destacar como variável, que o número de inscrições é majoritariamente masculino. Em 2016, por exemplo, para a proporção de $28 \%$ de aprovadas mulheres, o percentual de inscrições foi também de exatos $28 \%$, contra $70 \%$ de homens e outros $2 \%$ que não manifestaram o gênero. 


\subsection{A Fundação Lemann}

Importante apartar que a Fundação Lemann possui foco na educação, e que a análise que se fez e se descreve neste artigo tem por objeto seu programa de Líderes Públicos, um braço pequeno da instituição na comparação com seus outros quatro programas: Lemann Fellowship, Talentos da Educação, Talentos da Saúde e Terceiro Setor Transforma. A partir do ano de 2017, propôs-se a identificar, selecionar e capacitar potenciais candidatos a cargos eletivos. Foram 02 processos seletivos, um em 2017 e outro em 2018, que admitiram 20 líderes cada um, totalizando-se 40 líderes, portanto. O programa foi realizado em parceria com a RAPS, mas os selecionados, independentemente de pertencerem ou não a RAPS, passaram a ser considerados membros da Fundação Lemann. Destaca-se, no entanto, que, no primeiro processo seletivo, foram admitidos, ainda, 10 líderes na categoria ouvinte, mas que foram incorporados à rede, sendo que 01 participou também do segundo programa, o que elevou para 49 o número total de líderes.

Dito isso, tem-se que a Fundação Lemann é uma organização familiar constituída no ano de 2002. É presidida pelo empresário Jorge Paulo Lemann e administrada por um conselho composto de 06 membros, sendo 05 homens e 01 mulher. $\mathrm{O}$ diretor executivo é um homem, e a equipe executiva é formada por 32 membros, sendo 19 mulheres. Acreditam num "Brasil mais justo, inclusivo e avançado, com educação pública de qualidade e com pessoas que estão resolvendo os grandes desafios sociais do país" (LEMANN, 2019).

A formação dos líderes públicos com filiações a partidos diversos, passou por imersões que abarcaram questões centrais para os governos como saúde, educação e segurança pública, além de campanhas eleitorais, e ainda parte das turmas foram oportunizadas com eventos gratuitos e inteiramente pagos (passagem + hospedagem + alimentação) nas universidades de Oxford (2017) e de Zurique (2018). Não foram localizados dados que apontem o percentual de inscrições de homens e mulheres, mas das 20 lideranças selecionadas no primeiro processo, 13 são homens e 07 são mulheres, e das 20 selecionadas no segundo processo, 10 são homens e 10 são mulheres, o que alcançou a paridade. No total, entretanto, ainda há defasagem, já que as mulheres são $42 \%$. Se considerados as aprovadas e os aprovados na categoria "ouvintes" em 2017, tem-se 08 homens e 02 mulheres, $80 \%$ e $20 \%$ respectivamente, o que reduz o percentual geral para $38 \%$ de mulheres. 
Das 40 lideranças, por fim, ao menos 33 disputaram algum cargo na eleição geral de 2018, sendo 18 homens e 15 mulheres, ou 45\% do total. Tiveram êxito na eleição ao cargo que disputaram, por sua vez, 04 lideranças, sendo 02 mulheres e 02 homens, uma proporção paritária de 50\%, portanto. Se considerarem-se os ouvintes, no entanto, dos quais 03 foram eleitos, todos homens, sendo que 01 deles pertencente também à segunda turma, tem-se um total de 06 lideranças eleitas, sendo 02 mulheres e 04 homens, uma proporção de $33 \%$ e $66 \%$ respectivamente.

\subsection{O RenovaBR}

O RenovaBR, por sua vez, é uma organização da sociedade civil fundada e codirigida pelo empresário Eduardo Mufarej. Recebem doações de pessoas físicas e possuem 483 doadores, número atualizado até a finalização deste texto, embora tenham parcerias com outras organizações e até com empresas privadas. Em termos literais: "o RenovaBR foi criado em outubro de 2017 para preparar gente comprometida e realizadora para entrar na política. Focamos na renovação do Poder Legislativo e pautamos nossa preparação na atuação para futuros Deputados Federais e Estaduais" (RENOVABR, 2019).

Assim como os dois movimentos já descritos, após a admissão os novos membros passam por capacitações que envolvem educação, saúde pública, gestão fiscal e desenvolvimento social. A diferença mais relevante entre este movimento e os demais analisados é que, ao contrário daqueles, o RenovaBR só aceita inscrições e, consequentemente, só admite membros que nunca tiveram mandatos. Pode-se afirmar, assim, que todos buscam uma renovação de práticas na política, e esse, em particular, de práticas e pessoas.

A administração se realiza por sete membros, sendo 06 homens e 01 mulher, que é também a diretora executiva da entidade. A equipe de colaboradores conta com 12 membros, sendo 08 homens e 04 mulheres. Quanto aos líderes, são 133, excetuando-se os que recém foram aprovados em novo processo seletivo, sendo que, destes, 117 concorreram na eleição geral de 2018 para os mais diversos cargos, em diferentes partidos políticos. 17 foram eleitos, sendo 01 para o Senado Federal e os demais para Assembleias Legislativas estaduais e para a Câmara dos Deputados. Do total de líderes, 104 são homens e 29 são mulheres, que representam, portanto, $21 \%$. Considerando-se, por sua vez, o total que disputou a eleição geral de 
2018, 90 são homens e 27 são mulheres, que representam, portanto, 23\%. E, do total dos eleitos, 15 são homens e 02 são mulheres, que representam, portanto, $11 \%$, dentre elas a primeira indígena a ocupar o cargo de Deputada Federal no Brasil, Joenia Wapichana. Não há dados de gênero sobre os inscritos para o processo de seleção.

Tabela 1

\begin{tabular}{|c|c|c|c|}
\hline \multicolumn{4}{|c|}{ MULHERES ELEITAS NAS ELEIÇÕES GERAIS DE 2018 } \\
\hline & RAPS & Fundação Lemann & RenovaBR \\
\hline Número absoluto & 09 & 02 & 02 \\
\hline $\begin{array}{c}\text { Percentual em relação } \\
\text { ao total de eleitos }\end{array}$ & $23 \%$ & $33 \%$ & $11 \%$ \\
\hline
\end{tabular}

* Destaca-se que dentre as mulheres eleitas, conforme dados da tabela 1, há aquelas que pertencem a mais de um, e até aos três movimentos.

** O Deputado Federal Felipe Rigoni, embora membro da Fundação Lemann, não participou do programa de líderes públicos, razão pela qual não foi considerado para o cálculo.

\section{Considerações finais}

São muitos os campos de atuação que pedem uma presença feminina maior e mais igualitária, respeitosa e condizente com o seu conhecimento e sua capacidade de produzir. Ter mais mulheres liderando é, entre outras coisas, ter também mais políticas que digam respeito a aspectos concernentes às mulheres (MELO e THOMÉ, 2018, 1. 3093).

Assim, é difícil estabelecer uma relação que possa aferir, entre a participação das lideranças políticas nos processos de formação/capacitação dos três Movimentos de Renovação Política examinados e seus resultados eleitorais, mas é possível afirmar que, em alguma medida, eles foram importantes, especialmente para as candidaturas femininas, já que, notadamente a RAPS e a Fundação Lemann, mais a primeira que a segunda, esforçaram-se por proporcionar a Democracia Paritária na identificação e na seleção de seus membros. Ao menos três iniciativas com evidente relevância sob esse paradigma, no mais, passaram ou por um, ou por dois, ou mesmo pelos três movimentos: a Bancada Ativista, o Muitas, e o Gabinetona. Todas experiências de mandatos coletivos, compartilhados ou comandatos, terminologias que ainda carecem de definição na doutrina, mas que já se apresentam na narrativa de diversas campanhas eleitorais e mandatos. Outros mandatos femininos conquistados em 2018 passaram também pelas 03 enti- 
dades, como o da Deputada Estadual por São Paulo, Marina Helou (REDE), e o da Deputada Federal, também por São Paulo, Tábata Amaral (PDT).

A hipótese assim se confirma, e é possível concluir que os Movimentos de Renovação Política analisados contribuíram para a melhoria da representação feminina nos espaços de poder, notadamente em vagas das Assembleias Legislativas estaduais e da Câmara dos Deputados na eleição geral de 2018, mesmo que não se possa mensurar o impacto da atuação dessas organizações no resultado eleitoral e, particularmente, no resultado eleitoral de candidaturas femininas.

Nesse sentido, apresenta-se ainda como conclusão a evidência que se manifesta através das narrativas presentes nos documentos oficiais dos três Movimentos de Renovação Política estudados, que todos se constituem a partir de iniciativas de empresários do sudeste brasileiro, fundadas, por sua vez, no diagnóstico da crise da Democracia, com ênfase nas crises de representação e da própria Democracia brasileira.

De outro ponto, ainda que metodologicamente não seja admissível concluir, é necessário se considerar, no entanto, o fato de a literatura política e sociológica nacional e internacional revisada, embora destaque a necessidade da superação da crise da Democracia pelo próprio aprimoramento das práticas democráticas, não assinala que a Participação da Mulher na Política é fator fundamental para se alcançar melhores práticas inseridas na ideia amplamente reconhecida pelos autores daquilo que se tomou como Accountability democrática, em que a Democracia Paritária, como se pretendeu demonstrar também pela revisão bibliográfica, é parte indissociável, sobretudo tendo-se como pressuposto a necessidade de se transpor a crise da Democracia em geral, e da Democracia Liberal em particular.

Por fim, destaca-se a limitação da pesquisa apresentada no presente artigo, e a natureza de se propor para a mera contribuição da análise complexa do Feminismo como elemento fundamental na promoção de iniciativas que visem alcançar a Democracia Paritária. Também, e por consequência, recomenda-se maior olhar acadêmico e elaboração de trabalhos que aprofundem o pouco que se examinou, uma vez que subsistem variáveis que não foram alcançadas, e mesmo outras iniciativas semelhantes que, ainda que como hipótese, muito provavelmente tenham resultados relevantes para o referente apresentado na introdução, qual seja: modelos teóricos de promoção da participação feminina na política e experiências comparadas. 


\section{Referências}

ABRANCHES, Sérgio Henrique Hudson de. A Era do Imprevisto: a grande transição do século XXI. 1. ed. São Paulo: Companhia das Letras, 2017. . Polarização radicalizada e ruptura eleitoral. Em ABRANCHES, Sérgio Henrique Hudson de. et al. Democracia em risco?: 22 ensaios sobre o Brasil de hoje. São Paulo: Companhia das Letras, 2019.

. Presidencialismo de Coalizão: raízes e evolução do modelo político brasileiro. $1^{a}$ edição. São Paulo: Companhia das Letras, 2018.

BARROS, Celso Rocha de. Uma história de dois azares e um impeachment. Em ABRANCHES, Sérgio Henrique Hudson de. Et al. Democracia em risco?: 22 ensaios sobre o Brasil de hoje. São Paulo: Companhia das Letras, 2019.

BIROLI, Flávia Millena; MIGUEL, Luis Felipe. Feminismo e política. São Paulo: Boitempo Editorial. Edição do Kindle, 2014.

BOBBIO, Norberto. A Era dos Direitos. (trad.) Carlos Nelson Coutinho. Rio de Janeiro: Elsevier, 2004, p. 190.

CASTELLS, Manuel. Ruptura: a crise da democracia liberal. (trad.) Joana Angélica d'Ávila Melo. 1. ed. Rio de Janeiro: Zahar, 2018.

D’AVILA, Luiz Felipe. 10 mandamentos: do país que somos para o Brasil que queremos. 1. ed. Rio de Janeiro: Topbooks, 2017.

DIAMOND, Larry. O Espírito da Democracia: a luta pela construção de sociedades livres em todo o mundo. (trad.) Marcelo Oliveira da Silva. 1. ed. Curitiba: Instituto Atuação, 2015.

DOMINGUES, Petrônio. Democracia e Autoritarismo: entre o racismo e o antirracismo. Em ABRANCHES, Sérgio Henrique Hudson de. Et al. Democracia em risco?: 22 ensaios sobre o Brasil de hoje. São Paulo: Companhia das Letras, 2019.

ESMERALDINO, Herval Ângelo. A história do legislativo: 1860-2012. Itajaí: Câmara de Vereadores de Itajaí, 2012.

FUKUYAMA, Francis. Why Democracy is Performing So Poorly. Jornal of Democracy, Volume 26, n⿳⺈ 1 . National Endowment for Democracy and the Johns Hopkins University Press, Janeiro de 2015. 
GOHN, Maria da Glória. Mulheres - atrizes dos movimentos sociais: relações político-culturais e debate teórico no processo democrático. Política \& Sociedade, $\mathrm{n}^{\mathrm{o}}$ 11, outubro de 2007. Disponível em: https://periodicos.ufsc. br/index.php/politica/article/view/1255/1200. Acesso em: 19 jul. 2019. HARARI, Yhuval Noah. 21 lições para o século XXI. São Paulo: Companhia das Letras, 2018.

LEMOS, Ronaldo. Diante da realidade, seis ficções epistemológicas. Em ABRANCHES, Sérgio Henrique Hudson de. Et al. Democracia em risco?: 22 ensaios sobre o Brasil de hoje. São Paulo: Companhia das Letras, p. 196, 2019.

LEVITSKY, Steven; ZIBLATT, Daniel. Como as democracias morrem. (trad.) Renato Aguiar. 1. ed. Rio de Janeiro: Zahar, 2018.

MELO, Hildete Pereira de; THOMÉ, Débora. Mulheres e poder: histórias, ideias e indicadores. Rio de Janeiro: FGV a. Edição do Kindle, 2018.

MORIN, Edgar. As grandes questões do nosso tempo. Tradução de Adelino Santos Rodrigues. 6. ed. Lisboa: Notícias Editorial, 1999.

MOUNK, Yacha. O povo contra a democracia: por que nossa liberdade corre perigo e como salvá-la. Tradução de Cássio de Arantes Leite e Débora Landsberg. 1. ed. São Paulo: Companhia das Letras, 2019.

ONU, Mulheres e Parlamento Latino-Americano e Caribenho. Marco Normativo para Consolidar a Democracia Paritária. Disponível em: http:// www.onumulheres.org.br/wp-content/uploads/2018/06/Marco-Normativo-Democracia-Paritaria_FINAL.pdf. Acesso em: 19 jul. 2019.

ONU, Mulheres e Parlamento Latino-Americano e Caribenho. Nota Sobre Democracia Paritária. Disponível em: http:/ /www.onumulheres.org.br/ wp-content/uploads/2018/06/Nota_Democracia-Paritaria_FINAL.pdf. Acesso em: 19 jul. 2019.

PASSOLD, César Luiz. Metodologia da Pesquisa Jurídica: teoria e prática. 13. ed. Florianópolis: Conceito editorial, 2015.

PUTNAN. Robert David. Jogando boliche sozinho: colapso e ressurgimento da coletividade americana. (trad.) Marcelo Oliveira Silva. 1. ed. Curitiba: Instituto Atuação, 2015.

RODRIGUES JUNIOR, Álvaro. Liberdade de Expressão e Liberdade de Informação. Curitiba: Juruá. 2008. 
SISK, Timoth. Democracia em nível local: manual de participação, representação, gestão de conflito e governança do Internacional IDEA. (trad.) Patrícia Helena Rubens Pallu. 1. ed. Curitiba: Instituto Atuação, 2015. .<www.agoramovimento.com> Acesso em: 20 jul. 2019. .<www.cvi.sc.gov.br> Acesso em: 19 jul. 2019. .<www.eusoulivres.org> Acesso em: 20 jul. 2019. .<www.fundacaolemann.org> Acesso em: 20 jul. 2019. .<www.gabinetona.org> Acesso em: 20 jul. 2019. .<www.politize.com.br> Acesso em: 20 jul. 2019. .<www.raps.org.br> Acesso em: 20 jul. 2019. .<www.renovabr.org> Acesso em: 20 jul. 2019. .<www.transparenciapartidaria.org> Acesso em: 20 jul. 2019.

Níkolas Reis Moraes dos Santos - Graduado em Direito pela Universidade do Vale do Itajaí (UNIVALI), no ano de 2006. Mestre em Gestão de Políticas Públicas pela mesma instituição, no ano de 2015. Doutorando em Ciências Jurídicas pelo PPCJ-UNIVALI. Advogado e político, é, ainda, membro de organizações como a RAPS e a Fundação Lemann.

Vanessa de Ramos Keller - Graduada em Administração Pública pela Universidade do Estado de Santa Catarina (UDESC), no ano de 2009. Graduada em Direito pela Universidade do Vale do Itajaí (UNIVALI), no ano de 2012. Mestranda em Ciências Jurídicas pelo PPCJ-UNIVALI. Servidora do Ministério Público de Santa Catarina. 
